\title{
The [in]significance of New Zealand Wallpaper in the 1940s
}

Beth Chaney \& Sarah Rutledge, Studio Pacific Architecture, Wellington; Sophia Cogswell, School of Architecture, Victoria University, Wellington

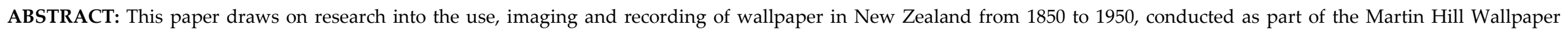

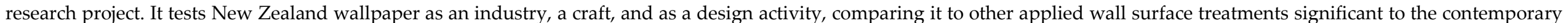

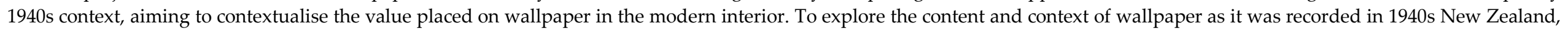

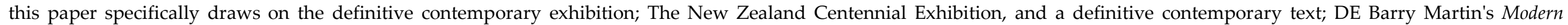

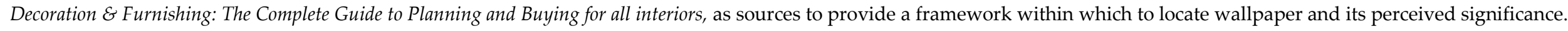

This paper draws on research into the use, imaging and recording of wallpaper in New Zealand from 1850 to 1950, conducted as part of the Martin Hill Wallpaper research project. Narrowing the focus of this research to the 1940s, it appears there is very limited evidence of the use, manufacture or advertising of New Zealand wallpaper during this time period. While others have suggested that the technology for the mass manufactory of wallpaper did exist in New Zealand at this time $^{1}$ the evidence from contemporary primary sources has proven scarce. However, the lack of contemporary documentation specific to New Zealand wallpaper itself does provide an opportunity to speculate upon possible factors that attributed to the scarcity of primary references to the New Zealand wallpaper industry, as either non-existent or marginalised. In this manner, such a

\footnotetext{
${ }^{1}$ Arden \& Bowman The New Zealand Period House p 208.
}

significant void of documentation may suggest that New Zealand wallpaper was either produced to such a limited or isolated extent that it was of negligible consequence at the time, and/or it was perceived as having such limited significance and value in contemporary society that its existence was not recorded. This paper will investigate the latter proposition, with the aim to contextualise the value placed on wallpaper in the Modern interior through an exploration of the content and context recorded in 1940s New Zealand. Specifically, the definitive contemporary exhibition, the New Zealand Centennial Exhibition, and a definitive contemporary text, Modern Decoration $\mathcal{E}$ Furnishing: The Complete Guide to Planning and Buying for all interiors ${ }^{2}$ have been closely investigated, with the value systems inherent within these sources providing a framework

${ }^{2}$ Barry Martin Modern Decoration \& Furnishing within which to locate wallpaper. Therefore, New Zealand wallpaper is tested as an industry, a craft, and as a design activity, with the findings compared to other applied wall surface treatments significant to the contemporary 1940s context, to establish the value associated with New Zealand wallpaper.

\section{The New Zealand Centennial Exhibition}

The New Zealand Centennial Exhibition was held in Rongotai, Wellington from 8 November 1939 to 4 May 1940 and formed the centrepiece for national celebrations of 100 years of colonisation. ${ }^{3}$ The influence of the Centennial Exhibition cannot be downplayed, with an attendance over the course of the exhibition of 2,641,043 people, and daily average attendance of $17,149 .{ }^{4}$ The aims of the

${ }^{3}$ Bowron A Brilliant Spectacle: The centennial Exhibition Buildings $\mathrm{p} 39$.

4 "The Centennial and progress" n.p. 
Exhibition can be clearly seen in the opening address given by the Governor General Lord Galway, who stated that "the exhibition will present a clear, unified and comprehensive picture of a century of modern progress and civilisation." 5 Futher, the Exhibition was described at the time as "the end of one epoch of national life and the starting place of renewed ideas and vision for the future." 6 The Centennial Exhibition therefore provided an avenue for critical reflection on the development of the Nation to date, a "historical stock-take"7 which was presented as a unified orchestration that embodied the aims of modernisation and progress. ${ }^{8}$ As such, the Exhibition can be seen as a significant mechanism for the distribution and propagation of contemporary value systems. Consequently, existing records of this exhibition provide a discourse through which the design, manufacture and display of New Zealand wallpaper can be investigated in a contemporary context.

${ }^{5}$ Bowron A Brilliant Spectacle: The centennial Exhibition Buildings $\mathrm{p} 39$.

${ }^{6}$ The Evening Post Clippings The Centennial Exhibition Closed 6 May 1940.

7 "The Centennial and progress" n.p.

${ }^{8}$ Bowron A Brilliant Spectacle: The centennial Exhibition Buildings $\mathrm{p} 39$.

\section{The Centennial Exhibition and Industry}

The potential contemporary value of wallpaper determined by the Centennial Exhibition can be investigated with regard to a closer reading of specific sections, or Courts, as physical manifestations of the aims of modern progress. The Manufacturing Industries section is particularly relevant as a clear reflection of the progressive aims of the exhibition, while also providing a potential location for the value of New Zealand wallpaper against other applied surface products. Manufacturing industry and its related mechanical processes and perceived innovation, ambition and advancement, can be appreciated as a product of the ideals of modernisation and progress the Exhibition strived to portray. This is seen in a contemporary commentary in The Evening Post which identified the display of "Industrial Progress" as one of the significant outcomes of the Exhibition. ${ }^{9}$ The significance of this section can be further appreciated due to the rare nature of such large scale industrial displays at the time. While Industrial Exhibitions and Trade Fairs had been popular in the nineteenth century, they became less common into the twentieth century, as "sales through

\footnotetext{
9 "The Centennial Exhibition Closed" p 9.
}

illustrated trade publications could advertise British and other manufacturers so much more cheaply and conveniently." 10 At the Exhibition, the combined displays forming the New Zealand Manufacturing Industries Court provided a unique opportunity for the representation and advertisement of local industry, as well as the "methods and materials involved in their production."11 As such, the New Zealand Manufacturing Industries Court of the Centennial Exhibition and associated documentation were of great significance as an outlet through which local industries could promote themselves in a prominent and unique context that strongly advocated modern ideals.

The exhibits forming the "New Zealand Manufacturing Industries Court" of the Centennial Exhibition were distinctly divided into classifications of "Art Industry," "Building Industry" and "Sundry Industry."12 The manufacture and development of products specific to the contemporary interior such as

${ }^{10}$ Calhoun The Arts and Crafts Movement in New Zealand 1870-1940 p 53.

11 Official History of the New Zealand Centennial Exhibition p 109.

12 New Zealand Centennial Exhibition, Official Catalogue p 20. 
wall decorations, paint and varnishes, textiles and leather, were each exhibited under one of the three distinct categories of industry listed above. However, the inclusion or display of wallpaper within the Industries Court ${ }^{13}$ is not recorded in official catalogues, ephemera, photography or in subsequent media reports on the Centennial Exhibition. While the development and progress of local industry of other interior surface decoration was exhibited, it may be assumed that wallpaper as an industry was not, even though the technology for mass manufacturing of wallpaper was possible at the time. ${ }^{14} \mathrm{~A}$ possible rationale for the exclusion of wallpaper from the Manufacturing Industries Court may be found in the compartmentalised nature of the Court layout and logic, which by its nature did not allow for wallpaper to be recognised as an industry by itself. While local development of various component industries associated with (but not solely connected with) the production of wallpaper were displayed, such as paper manufacturing and printing, each was distinct and disconnected from the other, located within separate buildings or blocks of the Exhibition

${ }^{13}$ New Zealand Centennial Exhibition, Official Catalogue p 20.

${ }^{14}$ Arden \& Bowman The New Zealand Period House p 208. grounds. ${ }^{15}$ This view aligns with the apparent disparity between the component industries of wallpaper and is further demonstrated in a wider context of industry outside of the Exhibition, free from restraints or overriding agendas of progress.

The contemporary Stone's and Wises directories do not contain any listings of local wallpaper manufacturers despite listing numerous local paper manufacturers and printers. It can therefore be surmised that the local production of wallpaper was not seen as a distinct and identifiable local industry worthy of mention, despite the various component industries of wallpaper making being both displayed and documented. It is possible that the collaborative nature of wallpaper manufacture prevented this product from being listed under any one distinct category at the exhibition or in contemporary directories, and hence not recognized, valued or recorded as a valid industry in its own right. It is of further note that no local wallpaper manufacturers are recorded in the official List of Exhibitors in the General Exhibits Court, ${ }^{16}$ an area that allowed

${ }^{15}$ Official History of the New Zealand Centennial exhibition $\mathrm{p}$ 14

${ }^{16}$ Official History of the New Zealand Centennial exhibition for "trade and miscellaneous displays," escaping somewhat the restrictions of industrial classifications evident in the Industries Court. Therefore, if the production of wallpaper was not aligned with the display of industrial progress and development that reflected the aims and values of the Exhibition, where can wallpaper be located within both the exhibition and its associated value structure?

\section{Centennial Exhibition: Wallpaper as craft, a "women's pastime"17}

To further understand the contemporary value of wallpaper, a further investigation into the records of the Exhibition will be discussed, focussing on the marginalised areas of the Exhibition that were potentially located outside of the notions of progress that the Exhibition was required to represent. The sole record of New Zealand wallpaper at the Centennial Exhibition can be traced to the Women's Section, which contained Fine Arts, and Arts and Crafts. ${ }^{18}$ Rather than recognised under an industry classification, and

\section{pp 144-116.}

${ }^{17}$ New Zealand Centennial Exhibition Official Catalogue p 61.

18 Official History of the New Zealand Centennial Exhibition p 104. 
subsequently displayed as a manufactured product aligned to "modern" themes of progress and innovation, wallpaper (in the form of design proposals) was presented within the context of the Arts and Crafts area of the Woman's Section, ${ }^{19}$ an area in itself separated from the main exhibition Courts. Within the "Woman's Section" were submissions for "designs for fabrics, textiles, wallpapers, etc.," 20 where a total of nine designs from three women were exhibited and deemed to be suitable for either textiles and wallpapers or both. The only available record of these is as follows:

Designs for fabrics, textiles, wallpapers, etc.

413. Burns, Mrs B Sinclair, Wellington: three charcoal panel drawings suitable for wallpaper or textiles.

414. Lumb, Mrs C, Lower Hutt, Wellington: three wall panels on white crepe de china.

415 Mather, Mrs K F, Winnipeg, Canada: one set of three designs for fabrics (for sale). ${ }^{21}$

No further references have been found to elaborate on this brief description, and there

${ }^{19}$ New Zealand Centennial Exhibition Women"s Section Catalogue p 37.

${ }^{20}$ New Zealand Centennial Exhibition Women"s Section Catalogue p 37.

${ }^{21}$ New Zealand Centennial Exhibition Women"s Section Catalogue p 37. are no images of these exhibition pieces to discern their style, colour and pattern. Furthermore there are no images or descriptions that describe the interior context within which the submissions were exhibited. As such, the only place that wallpaper was recorded was distinct and separate from the Industrial Court discussed above. Such a separation between the values placed on the Women's Section and the Industrial Court is evident in the description of the Women's Section, described at the time as "[a] collection of articles, form[ing] an interesting representation of the spare time activities of the woman of the dominion."22 As a spare time activity, women's craft could not be understood as an industry and therefore did not align to the same degree with contemporary ideals of "modern" which industry was seen to exemplify. This is evident in the physical location of the Woman's Section, in a seemingly prominent position on the main axis however dwarfed by the centennial tower which it was situated directly behind. Consequently, the framing of wallpaper within the context of the Woman's Section, a spare time activity, suggests that

${ }^{22}$ New Zealand Centennial Exhibition Official Catalogue p 61. wallpaper as displayed within the Exhibition was perceived as having a vastly different target audience to that of Industry. Contained within the specific context of the Women's Section of the Exhibition, it is of note that the potential existed for a public discourse on wallpaper within a lecture series that had a pivotal role in popularising the Women's Section, ${ }^{23}$ providing the only avenue through which wallpaper was officially presented within the Exhibition. In particular there were two lectures with titles that specifically made reference to ideas on interior decoration, ${ }^{24}$ alongside others of assumed similar status, for example, discussing the making of salad dressing. ${ }^{25}$ However, no further documentation has been found regarding the specific content of these lectures and as such the impact of these discussions, regarding the significance of wallpaper, remains unknown.

The significance and value placed on wallpaper in the Centennial Exhibition as a craft activity can therefore be understood as

23 "The Exhibition: Queen Patroness: Women's Section Important" p 18.

24 "Home furnishings and how to make the most of your possessions" p 43; "Colour schemes in the home" p 43.

${ }^{25}$ New Zealand Centennial Exhibition, Women"s Section Catalogue p 43. 
very modest. Only three wallpaper submissions were recorded as being submitted for public display, but such display was largely removed from main themes of the exhibition as a whole, by being carefully limited to the Woman's Section and therefore recorded and understood in relation to this specific context. As a "pastime activity" wallpaper design did not align with ideals of "modern progress and civilisation,"26 and it may be argued was thus separated from the displays of main Exhibition so as to achieve the overarching physical manifestation of a "clear, unified and comprehensive picture of a century of modern progress and civilisation." 27 Therefore it can be surmised that wallpaper was unable to be viewed as of any substantial value. However, to further investigate this notion, this paper will discuss the potential for the location of the value of wallpaper within this system to shift, through a reading of a definition of craft to test the location of wallpaper within the contemporary value system portrayed by the exhibition.

Howard Risatti's A Theory of Craft, while not a

${ }^{26}$ Bowron A Brilliant Spectacle: The Centennial Exhibition Buildings p 39.

27 "Eve of maturity: Lord Galway's address" p 10. text from the period, provides a definition of craft that can be used to provide a reading and insight into the separation strongly evident in the context of the Centennial Exhibition. In discussing the difference between "design" and "craft," Risatti states:

The great difference between them is that while the craftsman ends with a finished, functioning object, the designer does not. He or she ends up with a drawing or some other type of abstract notation that may, at a later stage, be made into an actual object; until it does, it remains an abstract sign- the term "design" itself comes from the Latin "signum," meaning sign. Thus, designing, as the making of a sign, is the first stage in... a two-stage process; only in the second stage is an actual object made.... reused as a physical entity, it will be by someone else or, more likely, by a machine during the second stage of the operation. ${ }^{28}$

Design therefore can be seen to be inherently linked with industry and manufacture, as it forms part of a process. Conversely, craft, as a completed and finished article, is separated from the process of design and industry. Assuming the relevance of Risatti's definition to a 1940s context, it appears significant that designs for wallpaper submitted to the Woman's Section of the Centennial Exhibition were collectively displayed in the context of

${ }^{28}$ Risatti $A$ Theory of craft $\mathrm{p} 147$. craft. As the production of wallpaper is a two stage process, its realisation relies on the existence of a symbiotic relationship between design and manufacture. Defining a specific design as craft negates the inherent links of the design and with industry, therefore subverting its potential for mass production. In the context of the Exhibition, wallpaper design recontextualised as craft can be understood as a means through which contemporary value systems devalued the significance of the realisation of specific products, such as wallpaper.

However, there is evidence from preceding and proceeding periods that even without the restrictions placed on wallpaper by the contemporary modern paradigm, the relationship between design and industry was disparate at best. This disparate relationship in New Zealand between design and industry, specific to wallpaper production, can be traced to as early as the $1880 \mathrm{~s}^{29}$ when wallpaper was first taught as a design to align with the current manufacturing principles with students taught specifically "decorative design ... suitable for reproduction on flat

${ }^{29}$ Calhoun The Arts and Crafts Movement in New Zealand 1870-1940 p 36. 
surfaces." 30 However, there is little evidence to suggest such designs were mechanically reproduced. ${ }^{31}$ Most wallpaper designs remained as abstract notations, submitted for art society competitions and industrial exhibitions, ${ }^{32}$ but never transformed into wallpaper proper. The closest link between design and industry can be found in an advertisement for H Leslie Friend in 1906, promoting services that facilitated the realisation of wallpaper designs. ${ }^{33}$ However modern methods of printing wallpaper were not employed, but rather the designs were hand-stencilled as opposed to machineprinted. It would be assumed that in the 1940s links between design and industry would be further apparent due to the pursuit of modern industry. However at the Centennial Exhibition, rather than a desire for a connection between design and industry, potential connections with specific regard to wallpaper were suppressed. Such a shift in attitude can be attributed to the overarching

${ }^{30}$ Calhoun The Arts and Crafts Movement in New Zealand 1870-1940 p 37.

31 "To Architects and Builders [advert]" p 77.

${ }^{32}$ Isabel Hodgkins, design for wallpaper, New Zealand Industrial Exhibition 1885. Calhoun The Arts and Crafts Movement in New Zealand 1870-1940 p 45.

${ }^{33}$ Calhoun The Arts and Crafts Movement in New Zealand 1870-1940 p 138. modern principles behind the Exhibition. The impact of these modern principles on the values associated with design and use of $\mathrm{New}$ Zealand wallpaper following the Centennial Exhibition can be further investigated through an analysis of a definitive contemporary text.

"The Complete Guide to Planning and Buying for all interiors" 34

In 1947 Modern Decoration and Furnishing: The complete guide to planning and buying for all interiors $^{35}$ was published, written by the prominent contemporary architect DE Barry Martin. This book became viewed as an authoritative contemporary text, described as being "to the interior of the 1940s house what the Edmond's Cookbook was to the kitchen and Yates Gardening Guide to the garden."36 The ideals pronounced in this source are significant as they aid the analysis and understanding of principles promoted through the content and official recording of the Centennial Exhibition six years earlier, by providing a definition of modern specific to the contemporary interior and surfaces treatments housed within.

\footnotetext{
${ }^{34}$ Martin Modern Decoration E Furnishing

${ }^{35}$ Martin Modern Decoration E Furnishing

${ }^{36}$ Keith A lovely day tomorrow: New Zealand in the 1940s $\mathrm{p}$ 32
}

Once again we come to use that word "modern," so hard to determine, yet so commonly used- or misused generally. In this book it is intended to describe an article as having qualities of design and construction which mark it as a true product of today's science and knowledge. ${ }^{37}$

While wallpaper at the Centennial Exhibition can be perceived as devalued because it did not fit into the broad ideas of modernity, Martin sets up a framework with which these broad ideas can be specifically applied to the interior. "To be really modern in the true meaning of the word"38 Martin states an object in the interior must be: "sincere, functional, attractive, well-made, well-produced, and labour-saving." 39 This list of criteria can be seen to form the basis for value judgements of various surfaces treatments including wallpaper. Although wallpaper did embody the ideas of the modern, promoted above, having "qualities of design" and employing manufacture in its process, it was by its very nature an applied surface treatment, and as a result discredited by Martin. He states that "good interior decoration is not merely an applied art, but an integral part of planning or

\footnotetext{
${ }^{37}$ Martin Modern Decoration E Furnishing p 47.

${ }^{38}$ Martin Modern Decoration E Furnishing p 47.

${ }^{39}$ Martin Modern Decoration E Furnishing p 47.
} 
architecture, with "good in all things" as its purpose." 40 Further, budgetary constraints of the time, imposed by the post World War II context, obliged many to follow the "high minded sentiments" 41 of Martin, of cleanliness, durability and efficiency for more practical purposes.

In Martin's text, the value and significance of wallpaper as a surface application was determined by comparison with interior surface treatments. Wallpaper was actively and directly seen as inferior product to paint: "[t]he author is of the opinion that wallpaper is not as attractive, or, in the long run, as satisfactory as painted walls." ${ }^{42}$ Such unquantifiable qualities of "unattractiveness" and "unsatisfactory-ness" are teamed with suggestions of scientific evidence, such that patterned wallpaper did not just breach contemporary aesthetic ideals but was also stated as proven to be detrimental to one's health,

Medical science has proved that interior decoration with restless patterns will possibly cause nervous ailments,

\footnotetext{
${ }^{40}$ Martin Modern Decoration E Furnishing p 8.

${ }^{41}$ Keith A lovely day tomorrow: New Zealand in the 1940s $\mathrm{p}$ 32.

${ }^{42}$ Martin Modern Decoration E Furnishing p 80.
}

and even general poor health to people who are not conscious of this ill effect, which is most noticeable with those who, after a tiring day's work, leave their offices for much needed rest, which they fail to find in the discordant rooms of their homes. ${ }^{43}$

Thus, while paint was advocated and popularised as "a true product of today's science and knowledge," 44 the use of wallpaper, (especially of the patterned variety) was actively discouraged by such scientific advancements and knowledge.

While wallpaper was discredited by Martin, as not an "integral part of planning or architecture," 45 it is of note that wallpaper designs did shift towards a modern aesthetic in an attempt to realign the value of wallpaper, even if not completely adhering to modern principles. A collection of images of New Zealand interiors in the 1940s and preceding decades reveals that in order for wallpaper to be aligned with the modern principles promoted at the time, the approach to the design of patterning, style and colour in wallpaper shifted to become increasingly subdued. In the preceding decades integrated floral designs were popular with a heavy

${ }^{43}$ Martin Modern Decoration E Furnishing p 21.

${ }^{44}$ Martin Modern Decoration \& Furnishing p 47.

${ }^{45}$ Martin Modern Decoration E Furnishing p 8. pattern that disguised the structural geometry inherent in a repeated pattern. However, in the 1940s these were replaced by geometric block patterns, namely stripes and trellis designs, or a subtly toned textured paper without pattern. ${ }^{46}$ Therefore, an attempt was made to align wallpaper with a wider contextual notion of the aesthetic qualities of the modern, and thus validate it, without necessarily following the prescriptive criteria for "modern" established in this definitive text.

A contemporary description of the newly completed McBeath House by architect Charles Fearnley, can be seen to parallel the principles advocated in Modern Decoration and Furnishing. Fearnley described his approach to the interior as having "walls and ceilings largely off-white as background for fabrics and furnishings." ${ }^{47}$ In order for wall surfaces to parallel Martin's avocation for the elimination of "restless patterns" 48 and to take a peripheral role, walls had to be decorated with either wallpaper heavily reduced in its extent of patterning or paint. By painting the interior walls of a house, as opposed to

${ }^{46}$ Conclusions drawn from analysis of wallpaper trends over decades: 1900-50.

47 "The McBeath House" p 2.

${ }^{48}$ Martin Modern Decoration E Furnishing p 21. 
hanging wallpaper, contemporary house owners were acting in accordance with the principle advocated by Martin, whereby the decorative treatments were understood as an integral component of a dwelling. ${ }^{49}$

This view can be examined in terms of the integral qualities of paint: paint bonds with a substrate, forming a solid and seamless surface, integral to the protection and longevity of the material onto which it is applied. As both a purposeful and integral part of the construction of a house, paint as a decorative medium could easily be seen to strongly align with the contemporary advocated principles above. The application of paint allowed a commonality between the exterior and interior surfaces of a dwelling, increasingly integrating a interior painted surface to the dwelling as a whole. Further, hardwearing paint products such as enamel were developed during the 1940s, 50 increasingly demonstrated the practicality, functionality and efficiency of this form of surface application, closely aligned to the modern requirements as prescribed in Modern Decoration and Furnishing.

${ }^{49}$ Martin Modern Decoration E Furnishing p 8.

${ }^{50}$ Keith A lovely day tomorrow- New Zealand in the $1940 \mathrm{~s} p$ 33.
The values placed on specific wall surface products can be further investigated through records of contemporary advertising, which formed the mechanism through which industry could publicly align itself with modern ideals specific to the contemporary interior. Martin's definition of "truly modern" products in the interior can be readily paralleled in the language utilised by a 1949 advertisement for newly developed enamel paint. The advertiser states that the paint is "exceptionally easy to apply, it gives a porcelain-like finish, a professional appearance. It stands up, month after month, to the hardest wear."51 Such a statement strongly mirrors the highly valued attributes of a modern interior to be "sincere, functional, attractive, well-made, well-produced, and labour-saving." 52 The advertising medium can also be seen as a way through which paint could be reinforced as embodying broader definitions of modern, in addition to those specifically aligned with its use as an interior product. Paint was furthermore valued as belonging to a distinct and identifiable local industry, with the advertisement displaying

51 "Ratex [advert]" p 40.

${ }_{52}$ Martin Modern Decoration \& Furnishing p 47 both a distinct brand name and manufacturer. Conversely, research into advertisements located within contemporary newspapers, popular women's magazines and periodicals has found no evidence of wallpaper contextualised as a specific New Zealand product, and as such aligned to industry. The increased significance and value associated with paint as an industry is further evidenced in contemporary trade directories, which recorded a marked increase in number of paint manufacturer listings throughout the 1940s. The Wellington, Taranaki and Hawke's Bay Stone's directories record a significant increase in the number of listings from five listings in 1930,53 to 17 by $1945 . .^{54}$ Conversely, as discussed earlier, while specific wallpaper merchants were listed as early as 1929,55 wallpaper manufacture was not listed as a distinct industry during this period. Consequently, the local paint industry by displaying itself as an innovative and developing industry, was aligned with contextual values of "modern" that formed the

53 Stone's Wellington, Hawke"s Bay \& Taranaki Directory 1930.

54 Stone's Wellington, Hawke"s Bay \& Taranaki Directory 1945.

55 Stone's Wellington, Hawke"s Bay \& Taranaki Directory 1929. 
framework and basis for judgements of value, as publicised within Martin's text, and also augmented at the Centennial Exhibition. Wallpaper, therefore was not understood to be contextualised within the same value parameters as paint, and therefore valued significantly differently.

\section{Conclusion}

This paper has investigated the potential value of wallpaper as defined in records acknowledged as key markers of the 1940s New Zealand context. Through the close investigation of the value systems inherent in the New Zealand Centennial Exhibition, and Modern Decoration \& Furnishing: The Complete Guide to Planning and Buying for all interiors, 56 the status of New Zealand wallpaper across both these sources is acknowledged as of little value. Through the testing of the value of New Zealand wallpaper as an industry, a craft, a design activity, and compared to other applied wall surface treatments significant to the contemporary 1940s context, it has become apparent that wallpaper could not be clearly categorized within a framework maintained by modern ideals, and therefore could not be valued as significant. Consequently, although the scale of local wallpaper manufacture during this period cannot be clearly determined, this paper has established that it is plausible that the lack of recorded information regarding wallpaper in the 1940s may be a direct consequence of the value placed on wallpaper at this time.

\footnotetext{
${ }^{56}$ Martin Modern Decoration E Furnishing
} 


\section{REFERENCES}

Arden, Stuart and Ian Bowman The New Zealand Period House: A Conservation Guide, Auckland: Random House, 2004.

Bowron, Greg "A Brilliant Spectacle: The Centennial Exhibition Buildings" Zeal and Crusade: The Modern Movement John Wilson (ed) Wellington, Christchurch, N.Z: Te Waihora Press, 1996:39-46.

Calhoun, Ann The Arts and Crafts Movement in New Zealand 1870-1940 Auckland, N.Z.: Auckland University Press, 2000.

"The Centennial and progress - New Zealand Centennial, 1940" New Zealand History online URL: http://www.nzhistory.net.nz/culture/centennial/the-centennial-andprogress (Ministry for Culture and Heritage) (updated 18 January 2008).

"The Centennial Exhibition Closed" The Evening Post (Monday 6 May 1940):9.

Clark, Justine \& Paul Walker Looking for the Local: Architecture and the New Zealand Modern, Wellington, N.Z: Victoria University Press, 2000.

Cochran, Christopher Restoring a New Zealand House: Prepared for the New Zealand Historic Places Trust, 1980.

"Colour schemes in the home" New Zealand Centennial Exhibition Women's Section Catalogue Wellington, 1939-1940:43.

Dalley, Bronwyn and Bronwyn Labrum Fragments: New Zealand Social and Cultural History, Auckland, N.Z: Auckland University Press: 2000.

"Eve of maturity: Lord Galway's address" The Evening Post (8 November 1939):10.

"The Exhibition: Queen Patroness: Women's Section Important" The Evening Post (2 June 1938):18.

"Home furnishings and how to make the most of your possessions" New Zealand Centennial Exhibition Women's Section Catalogue Wellington,
1939-1940:43.

Jackson, Lesley Twentieth Century Pattern Design: Textile and Wallpaper Pioneers, New York: Princeton Architectural Press, 2002.

Keith, Hamish A lovely day tomorrow: New Zealand in the 1940s Auckland: Random Century New Zealand Ltd, 1991.

Lloyd Jenkins, Douglas At Home: A Century of New Zealand Design, Auckland (N.Z): Godwit, 2004

"The McBeath House" New Zealand Design Review (February-March 1949) $1(5): 2$.

Macdonald, Charlotte The Vote, the pill and the demon drink: A History if Feminist Writing in New Zealand 1869-1993, Wellington (N.Z): Bridget Williams Books, 1993.

Martin, D.E. Barry Modern Decoration \& Furnishing: The Complete Guide to Planning and Buying for all interiors Wellington, N.Z: A.H. \& A.W. Reed, 1947.

Museum of New Zealand Te Papa Tongarewa: collections online, http://collections.tepapa.govt.nz/

"The New Centennial, 1940" http://www.nzhistory.net.nz/culture/nz-centennial-1940 (Ministry for Culture and Heritage) (updated 4 February 2008).

New Zealand Centennial Exhibition Official History of the New Zealand Centennial exhibition Wellington: 1939-1940.

New Zealand Centennial Exhibition The Centennial Exhibition Official Catalogue Wellington: 1939-1940.

New Zealand Centennial Exhibition Women's Section Catalogue Wellington: 1939-1940.

New Zealand Department of Internal Affairs Making New Zealand: Pictorial Survey of a Century: Volume 1 Auckland: Wilson and Horton Ltd, 1940. 
New Zealand Department of Internal Affairs Making New Zealand: Pictorial Survey of a Century: Volume 2 Auckland: Wilson and Horton Ltd, 1940.

Petersen, Anna K. C. New Zealanders at Home: A Cultural History of Domestic Interiors 1814-1914 Dunedin: University of Otago Press, 2001.

"Raytex [advert]" Newsview (March 1949) 5(43):40

Risatti, Howard A Theory of craft: function and aesthetic expression Chapel Hill: The University of North Carolina, 2007.

Salinger, Lesleigh "A Breath of Fresh Air: The Architectural Centre Inc." Zeal and Crusade: The Modern Movement in Wellington, Christchurch:Te Waihora Press, 1996:69-78.

Salmond, Jeremy Old New Zealand Houses 1800-1940 Auckland: Reed Methuen, 1986.

Saunders, Gill Wallpaper in Interior Decoration London: V\&A, 2002.

Shaw, Peter A History of New Zealand Architecture Auckland, N.Z.: Hodder Moa Beckett, 1997.

Shelton, Vivien \& J \& J Siers A Guide to Home Decorating in New Zealand Wellington: Reed, 1971.

Stewart, Di The New Zealand Villa: Past and Present New Zealand: Penguin Books Ltd, 1992.

Stone's Wellington, Hawke's Bay E Taranaki Directory 1929 Dunedin, N.Z.: Stone, Son \& Co, 1929.

Stone's Wellington, Hawke's Bay E Taranaki Directory 1930 Dunedin, N.Z.: Stone, Son \& Co, 1930.

Stone's Wellington, Hawke's Bay E Taranaki Directory 1945 Dunedin, N.Z.: Stone, Son \& Co, 1945.

Stone's Canterbury, Marlborough \& Westland Directory 1945 Dunedin, N.Z.: Stone, Son \& Co, 1945.

Stone's Otago \& Southland Directory 1945 Dunedin, N.Z.: Stone, Son \& Co,
1945.

"To Architects and Builders [advert]" Progress (1 January 1909):77.

Wellington City Library (Central) The Evening Post Clippings: 1940 The Centennial Exhibition, Folders A-H.

Wises Auckland Provincial Directory 1946 Dunedin, N.Z.: H. Wise \& Co (N.Z), 1946. 